\title{
A importância da medição da temperatura em conexões a serem substituídas ou reparadas em redes de média tensão por equipe de manutenção de rede aérea energizada (Linha Viva)
}

The importance of temperature measurement in connections to be replaced or repaired on media voltage networks by energized air network maintenance team (Live Line)

Israel Cesar Rodrigues Alves ${ }^{\dagger *}$, Alex Franco Ferreira

Como citar esse artigo. Alves, ICR; Ferreira, AF. A importância da medição da temperatura em conexões a serem substituídas ou reparadas em redes de média tensão por equipe de manutenção de rede aérea energizada (Linha Viva). Revista Teccen. 2019 Jul/Dez; 12 (2): 59-67.

\begin{abstract}
Resumo
As companhias elétricas ao longo dos anos buscam formas de melhoria em seus processos de distribuição de energia elétrica em relação as perdas técnicas. Essas companhias em sua maioria utilizam na manutenção preventiva o instrumento de medição de temperatura chamado termovisor, que tem a função de constatar pontos quentes encontrados em conexões, cabos e equipamentos. Este trabalho tem por objetivo explicar a importância da medição da temperatura para substituição ou reparo de conexão por equipe de manutenção em redes aéreas energizadas (Linha Viva), com o foco na segurança. A sequência metodológica deu-se a partir de um levantamento sobre as perdas não técnicas de instalações elétricas que o autor apresentou no trabalho de conclusão do curso de bacharel em engenhariaelétrica, inclui também definições, classificações, tipos e locais onde propiciam os problemas de perdas nas instalações elétricas. Foram relatados conceitos de física térmica, estudou se o uso do instrumento denominadotermovisor no plano de ações/medidas. Como resultado espera-se conscientizar o leitor da importância de realizar a inspeção termográfica antes da atividade de substituição ou reparo de conexões em redes de média tensão. Conclui-se que com a correta medição com o equipamento termovisor na aplicação de detecção de pontos quentes, causados pela corrente elétrica em instalações elétricas de média tensão, tornase possível gerar uma proposta de implementação de medidas e ações que venham trazer benefícios para a segurança dos eletricistas e a confiabilidade no sistema elétrico.

Palavras-Chave: Inspeção termográfica, Inspeções em redes de baixa tensão, Segurança em instalações, NR-10, Termografia em inspeções.
\end{abstract}

\begin{abstract}
Electric companies over the years have been looking for ways to improve their power distribution processes over technical losses. These companies mostly use for preventive maintenance the temperature measuring instrument called thermal imager, which has the function of finding hot spots found in connections, cables and equipment. This paper aims to explain the importance of temperature measurement for connection replacement or repair by maintenance personnel in live overhead lines (Live Line), with a focus on safety. The methodological sequence was based on a survey on the non-technical losses of electrical installations that the author presented in the final work of the bachelor's degree in electrical engineering. It also includes definitions, classifications, types and places where the problems of losses provide. in electrical installations. Thermal physics concepts were reported and the use of the thermal imager in the action / measurement plan was studied. As a result, it is expected to make the reader aware of the importance of performing thermographic inspection prior to the activity of replacement or repair of connections in medium voltage networks. It is concluded that with the correct measurement with the thermal imager equipment in the application of detection of hot spots caused by the electric current in medium voltage electrical installations, it is possible to generate a proposal of implementation of measures and actions that may bring benefits to the safety of electricians and reliability in the electrical system.

Keywords: Thermographic inspection, Inspections in low voltage networks, Security in facilities, NR-10 and Thermography in inspections.
\end{abstract}




\section{Introdução}

Segundo Alves (2017), com a tecnologia evoluindo ao longo dos anos as empresas vêm estudando maneiras de trabalhar com equipamentos para melhorar seus sistemas de perda de energia. As companhias elétricas utilizam um instrumento de medição de temperatura chamado termovisor que realiza a detecção de emissão de calor por dispositivos, equipamentos e sistemas destacando-se as técnicas de imageamento térmico (termografia) como perfeitamente adequadas para tais monitoramentos.Por sua vez tem a função de detectar pontos quentes em conexões de redes elétricas e equipamentos ajudando a diminuir as perdas técnicas.

Este trabalho teve por objetivo utilizar o equipamento termovisor na aplicação de detecção de pontos quentes causados pela corrente elétrica em instalações elétricas em redes de média tensão com o foco na segurança.

A realização deste estudo se deu dentro de uma sequência metodológica que envolveu inicialmente um levantamento sobre as perdas técnicas de instalações elétricas, incluindo também sua definição, classificação, tipos e os locais onde podem propiciar os maiores problemas de perdas de energia em uma instalação elétrica. Foi relatadoconceito sobre técnicas de termografia, com o intuito de apresentar procedimentos/ ações padrões a serem previstas na proposição de um plano de ações/medidas, com vistas a conscientizar a importância para a segurança dos eletricistas de linha viva e a confiabilidade do sistema elétrico.

\section{Equipamentos de segurança}

No mundo atual a energia elétrica é indispensável para a sociedade, em contrapartida essa dependência dos usuários vem se traduzindo em exigências por melhor qualidade de serviço prestado pelas concessionárias distribuidoras de energia. Para garantir essa qualidade de atendimento e diminuir as interrupções no fornecimento de energia, as empresas começaram a desenvolver e utilizar técnicas de manutenção com a rede elétrica energizada, conhecida como técnica de linha viva conforme mostrada na Figura 1. A partir de então, iniciou-se o desenvolvimento de metodologias e ferramentas que pudessem ser utilizadas para realizar a manutenção em linha viva, ou seja, sem a desenergização da rede elétrica.

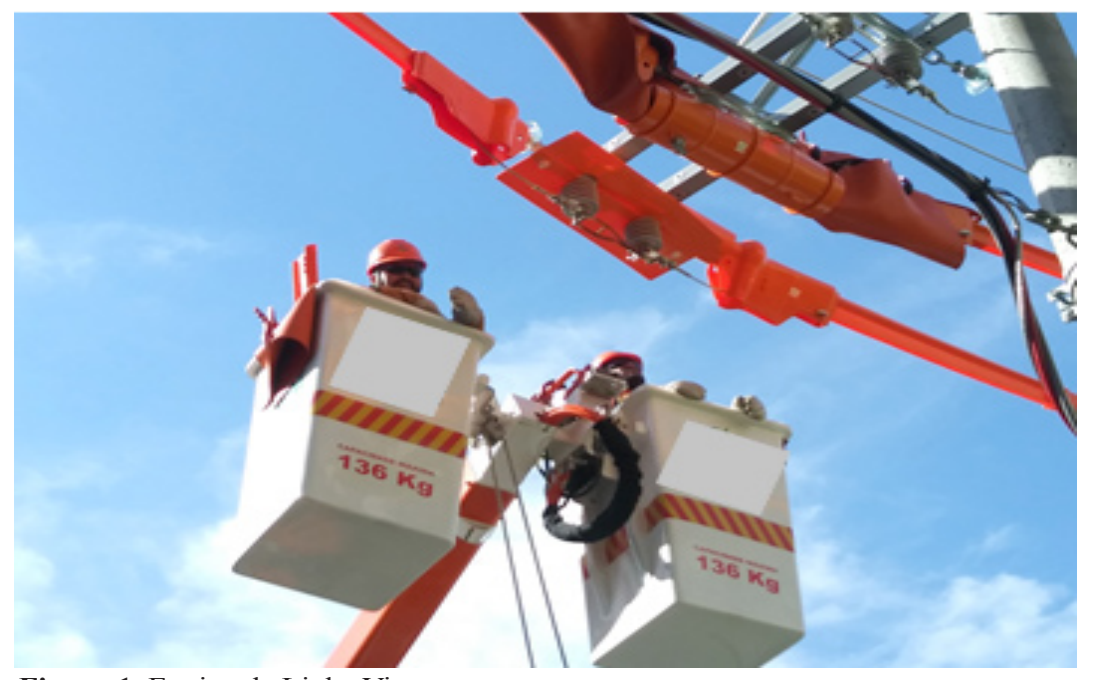

Figura 1. Equipe de Linha Viva

Fonte: Do Autor, 2019.

Os equipamentos de segurança denominados de EPI (Equipamento de proteção individual) e EPC (Equipamento de proteção coletivo), normalmente são aplicados pelas equipes que realizam a manutenção de redes, com o objetivo de isolar as fases onde não se realiza o trabalho ou partes do conjunto que estejam aterradas.

Deve-se isolar todas as partes do conjunto onde se trabalha, pois estas podem apresentar potencial elétrico induzido pela rede, além do eletricista que ao executar o trabalho próximo à rede, tem nele um potencial elétrico induzido. Assim deve-se realizar a atividade de forma isolada.

De acordo com Terex Ritz (2018), as coberturas rígidas ou de borracha natural empregada, possuem o papel de isolar as partes energizadas consideradas de risco ao eventual contato do eletricista.São produzidas com termoplástico de alta rigidez dielétrica, normalmente o polímero utilizado é o polietileno de alta densidade (PEAD ou HDPE). Dentre os principias equipamentos utilizados estão a cobertura de isolador, 
cobertura de cruzeta, cobertura circular, cobertura para poste e a cobertura de condutor, que pode ser visualizada na Figura 2.

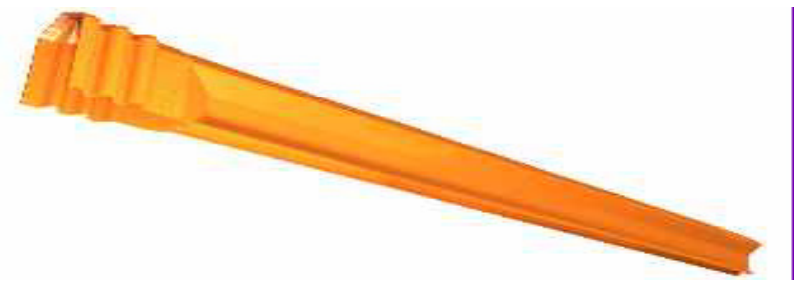

Figura 2. Protetor isolante tipo calha para condutor. Fonte: Terex Ritz, 2018.

O material empregado na fabricação da luva isolante como mostra a Figura 3 utilizada pelos eletricistas é confeccionado em uma matriz de borracha natural, ou EPDM. As propriedades ótimas dentro da aplicação desejada são obtidas por meio da mistura destas matrizes à cargas e aditivos. A massa obtida desta mistura é dissolvida em solvente dando ao material um aspecto líquido. Moldes na forma da luva são imersos neste material dissolvido tantas vezes quanto necessário para se obter a espessura desejada. Após este processo segue a vulcanização que confere à luva as propriedades desejadas.

Afirma Orion S.A (2018), que as luvas são fabricadas de forma a ter uma espessura que permita o material suportar um campo elétrico da ordem de 15 $\mathrm{MV} / \mathrm{m}$. Assim as luvas isolantes, são divididas em seis classes de isolamento, sendo estas $00,0,1,2,3$ e 4 para isolamento das tensões de $0,5 \mathrm{kV}, 1 \mathrm{kV}, 7,5 \mathrm{kV}, 17 \mathrm{kV}$, $26,5 \mathrm{kV}$ e $36 \mathrm{kV}$.

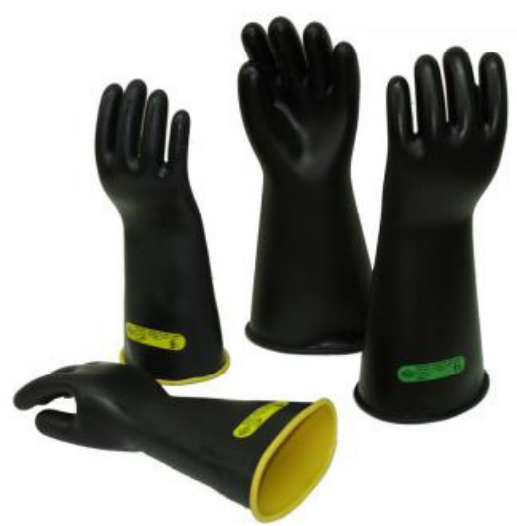

Figura 3. Luvas isolantes classe 2 e 3. Fonte:Orion S.A, 2018
A exemplo das luvas isolantes, as mangas isolantes são confeccionadas em uma matriz de borracha natural ou Etileno propileno-dieno monômero (EPDM), seguindo os mesmos princípios de formulação do material empregado na fabricação de luvas isolantes. Podem ser confeccionadas pelo processo de imersão ou pintura do molde, ou ainda pelo processo determoprenssagem ou moldadas. (Orion S.A, 2010)

As mangas isolantes são comercializadas em dois modelos ou estilos diferentes, sendo um deles a chamada manga reta e o outro a manga curvada, como mostra a Figura 4. Diferente das luvas isolantes, as mangas isolantes são divididas em apenas 5 classes, sendo estas $0,1,2,3$ e 4, para tensões de uso de $1 \mathrm{kV}$, $7,5 \mathrm{kV}, 17 \mathrm{kV}, 26,5 \mathrm{kV}$ e $36 \mathrm{kV}$ respectivamente. (Orion S.A, 2010)

Esse equipamento é utilizado pelos eletricistas somente para evitar eventuais contatos com equipamentos ou cabos energizados.

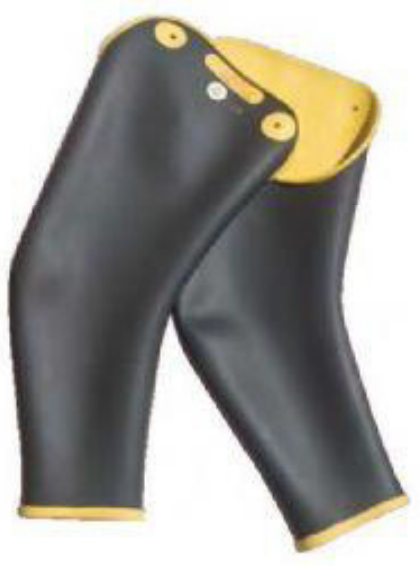

Figura 4. Manga isolante classe 2. Fonte: Orion S.A, 2018.

Terex Ritz(2018), afirma que os lençóis isolantes como mostra a Figura 5, são confeccionados em borracha natural, ou polímero equivalente e, portanto, seguem as mesmas classes de isolamento das mangas isolantes e luvas isolantes confeccionadas em borracha natural e sua classe de isolamento 4 .

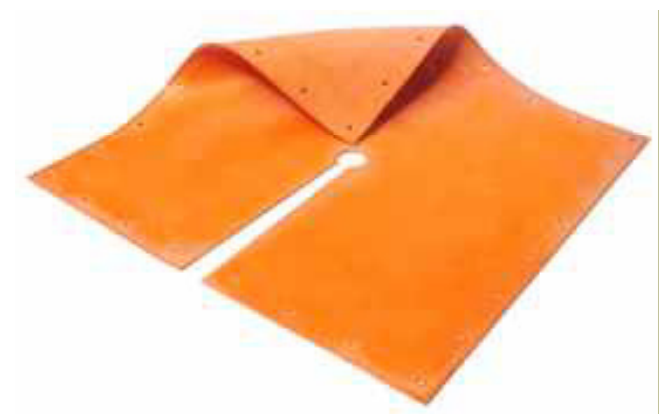

Figura 5. Lençol isolante classe 3. Fonte: Terex Ritz, 2018. 


\section{Termometria}

A termometria é a parte da termologia voltada para o estudo da temperatura e divide-se em duas áreas de acordo com o princípio de medição sendo a radiometria e a de contato (VIANA, 1991).

\section{Análise termográfica}

De acordo com a ABNT NBR 15424 (2013) análise termográfica ou medição radiométrica é a técnica de sensoriamento remoto, na qual as medições de temperatura são realizadas empregando-se sensores que não estão em contato físico com os objetos em análises se baseiam na detecção da radiação eletromagnética naturalmente emitida pelos corpos em função de sua temperatura absoluta. Estes sensores podem ser fotocondutivos, fotovoltaicos ou térmicos (bolômetro).

Detectores do tipo bolômetro ou micro bolômetro são dispositivos, diferentemente dos detectores quânticos fotoresistores e fotovoltaicos, que não funcionam de forma quântica, apenas absorvem o calor, aquecendo-o o dispositivo, com isto alterando sua resistividade de forma sensível. (ALBUQUERQUE, 1995).

\section{Termovisão}

Pinto (2013) explica que a Termovisão é baseada na técnica de visualizar, captar as imagens térmicas a partir de radiações térmicas invisíveis a olho nu, na faixa do infravermelho, constantemente emitidas, absolvidas e reemitidas pelos corpos e objetos.

\section{Câmera termográfica ou imageador térmico}

Pinto (2013) define Câmera termográfica ou
Imageador térmico como:

Câmera termográfica ou Imageador térmico é um equipamento que detecta energia térmica em sinal eletrônico, produzindo imagens em padrão de TV/Vídeo e executando cálculos de temperatura.(Pinto, M. T., 2013)

Na Figura 6, mostra-se o modelo utilizado na inspeção termográfica, que emprega microbôlometros como elemento sensível ás emissões térmicas, e suas respectivas especificações.

\section{Propostade ações/diretrizes na segurança das instalações elétricas em rede de distribuição de energia com foco em termografia para as atividades de turma de manutenção em rede aérea energizada (Linha Viva).}

O presente trabalho se propôs apresentar sugestões para o desenvolvimento de um plano de ação com o foco na segurança dos eletricistas de linha viva e a confiabilidade do circuito elétrico, envolvendo a implementação de ações/diretrizes para a realização de inspeções nas instalações elétricas de distribuição de energia, através de técnicas de inspeções baseadas no uso de equipamento de imageador térmico. As ações referemse basicamente ao acompanhamento por monitoramento sistemático das condições de temperaturas, para evidenciar a evolução destas condições térmicas assim constatando as irregularidades podendo ser assegurar melhores condições de segurança.

$\mathrm{Na}$ implementação do plano, foram definidas ações de inspeções na rede de distribuição de energia de uma companhia elétrica que possui padrão de rede aérea, sendo assim os inspetores tendo facilidade para inspecionar a instalação de forma completa, com a

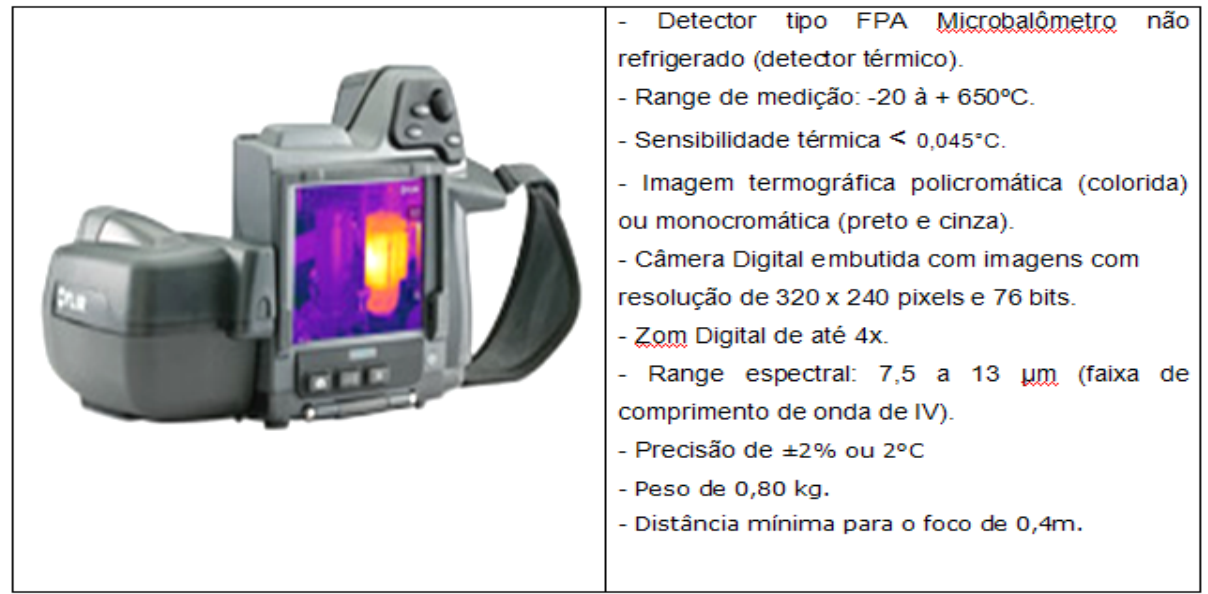

Figura 6. Modelo da câmera utilizada na inspeção termográfica. 
aplicação proposta nesse presente trabalho cita que o equipamento de termografia pode diagnosticar e evidenciar nos casos citados uma irregularidade na instalação elétrica.

\section{Efeitos da temperatura sobre os cabeamentos}

De acordo com Terex Ritz (2019), um condutor com uma determinada corrente elétrica apresentando uma temperatura acima de $70{ }^{\circ} \mathrm{C}$ com um tempo de exposição em 7 horas pode causar danos aos materiais isolantes, sendo luvas e mangas isolantes.

A exposição ao calor é causada para acelerar o processo de degradação do material. Aamostra de borracha natural foi acondicionada em estufa, na temperatura de $90{ }^{\circ} \mathrm{C}$, para se realizar o envelhecimento térmico. As amostras lençol isolante de borracha naturalestudada foram envelhecidas termicamente por um período de 45 dias tendo um alongamento de $67 \%$ segundo o ensaio de (Hernaski, 2010).

Considerando o estudo de Hernaski (2010), temse como paramêtro sobre a exposição das coberturas, sendo que os casos 1, 2, 3 e 4 apresentados nesse trabalho mostraram temperaturas elevadas, expondo-as a sobretensões térmicas ao longo das atividades.

Conforme enuncia Hernaski (2013), a exposição ao calor é usada para acelerar os processos de degradação, causando o envelhecimento térmico. Tal processo de envelhecimento térmico ocorre quando o sistema elétrico está sujeito a elevadas temperaturas, onde os mecanismos a ele associados são termicamente ativados, tais como polimerização, despolimerização, oxidação, quebra de cadeias e ligações.

Para Coutinho et al. (2003), a linearidade das cadeias e consequentemente a maior densidade do PEAD fazem com que a orientação, o alinhamento e o empacotamento das cadeias sejam mais eficientes; as forças intermoleculares (Van der Waals) possam agir mais intensamente, e, como consequência, a cristalinidade seja maior que no caso do PEBD. Sendo maior a cristalinidade, a fusão poderá ocorrer a temperaturas mais altas, sendo entre 128 a $135^{\circ} \mathrm{C}$.

Pode-se afirmar que os ensaios das coberturas isolantes são realizados segundo o Ministério do trabalho (2004) afirma na norma regulamentadora NR10 , num período de 1 ano, por sua vez considerando uma turma de linha viva trabalhando 8 horas por dia durante 22 dias, resultando em 1 ano cerca de 2112 horas de exposição, podendo assim ficar vulnerável a condição de segurança da equipe e do sistema elétrico até a chegada do próximo ensaio elétrico.

\section{Procedimentos de inspeção e suas recomendações}

O procedimento geral é produto da revisão de diversos artigos publicados, de normas internacionais dirigidas à termografia e adotadas por diversas empresas do setor de energia brasileira e relatada por Santos (2006), sendo eles:

- Iniciar a inspeção, preferencialmente, uma hora após o pôr do sol. Na necessidade de inspeções diurnas, recomenda-se que a inspeção seja realizada preferencialmente em até uma hora e meia após o nascer do sol ou também em dias nublados para evitar carregamento solar;

- Adaptar o termovisor as distâncias adequadas e as dimensões dos pontos a ser inspecionada, na maioria das situações encontradas nas subestações uma lente de campo de visão entre $10^{\circ}$ até $25^{\circ}$ são suficientes;

- Ajustar a emissividade do termovisor entre 0,85 até 0,95 ;

- Ajustar o foco da câmera para a melhor condição a fim de se evitar erros de leitura;

- Realizar a inspeção de acordo com a rota de inspeção pré-estabelecida;

- Registrar as medidas de temperatura ambiente e umidade relativa do ar;

- Evitar inspeções com umidade relativa do ar acima de $90 \%$;

- Após a ocorrência de chuva, esperar no mínimo 1 (uma) hora para iniciar

\section{Equipamento de proteção individual (EPI)}

Uma das grandes vantagens da termografia é a realização da inspeção sem interrupção da energia, isto é, com os equipamentos energizados e sob carga. Por essa razão o cumprimento das normas de segurança comuns à área a ser inspecionada deve ser rigorosamente observadas e a utilização dos EPI's deverá ser de uso obrigatório, assim em inspeções em subestações desabrigadas, segundo Alves (2017), deverá possuir os seguintes EPI's:

- Capacete;

- Óculos de segurança;

- Calçado de segurança, com solado para riscos elétricos;

- Vestimentas antichama aprovado e com certificado de aprovação (CA). 


\section{Desenvolvimento do plano e Análise de casos}

Para que o plano seja eficiente é necessário que as inspeções sejam realizadas antes do início da atividade, pois poderá não encontrar a temperatura correta para o trabalho conforme as citações de estudos de envelhecimento térmico e o fabricante das proteções isolantes, sendo realmente constatada irregularidade quando houver a certeza que existe um terminal de chave ou conexão que apresenta uma determinada corrente elétrica e obtendo um valor térmico excedente aos padrões de exposição das proteções isolantes a equipe poderá utilizar o direito de recusa conforme legislação.

Caso 1: Conforme a Figura 7, registrada durante o período diurno.

Foi detectada a imagem térmica, sendo a temperatura mostrada na Figura $8 \mathrm{em}$ uma chave seccionadora ao qual a fase do meio (B) apresenta $96,8{ }^{\circ} \mathrm{C}$, colocando os materiais isolantes em risco e a segurança da equipe de manutenção em rede aérea

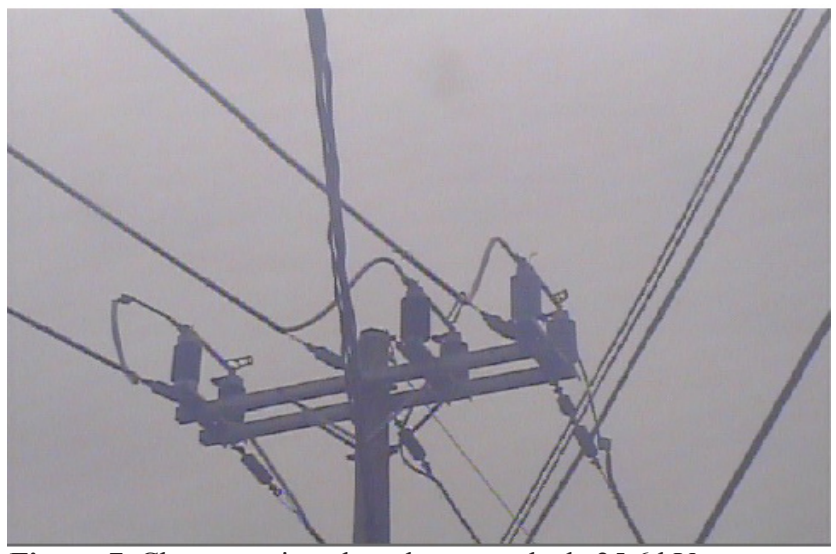
Figura 7. Chave seccionadora de uma rede de $25,6 \mathrm{kV}$.
Fonte: Do Autor, 2019.

energizada (Linha Viva).

Plano de ações/medidas que podem ser tomadas:

- Recomenda-se a desenergização da rede conforme a Nr-10;

- Realizar manobras nos alimentadores paralelos dando recurso, fazendo assim a diminuição do carregamento do circuito e a redução do valor da temperatura;

- Realizar manobras para deixar essa chave seccionadora em paralelo.

Caso 2: análise de uma Chave seccionadora de uma rede de 13,8 kV,conforme a Figura 9, registrada durante o período diurno.

$\mathrm{Na}$ chave da Figura 9 foi detectada a imagem
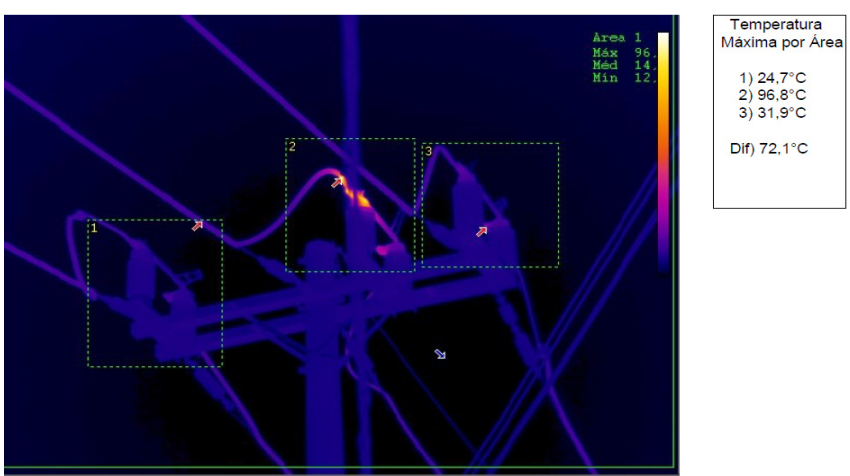

Figura 8. Termograma de uma imagem térmica na chave seccionadora de uma rede de $25,6 \mathrm{kV}$.

Fonte: Autor (2019).

térmica, sendo a temperatura mostrada na Figura $10 \mathrm{em}$ uma chave seccionadora ao qual a fase da rua (de fora) (A) apresenta $95,2^{\circ} \mathrm{C}$, colocando os materiais isolantes

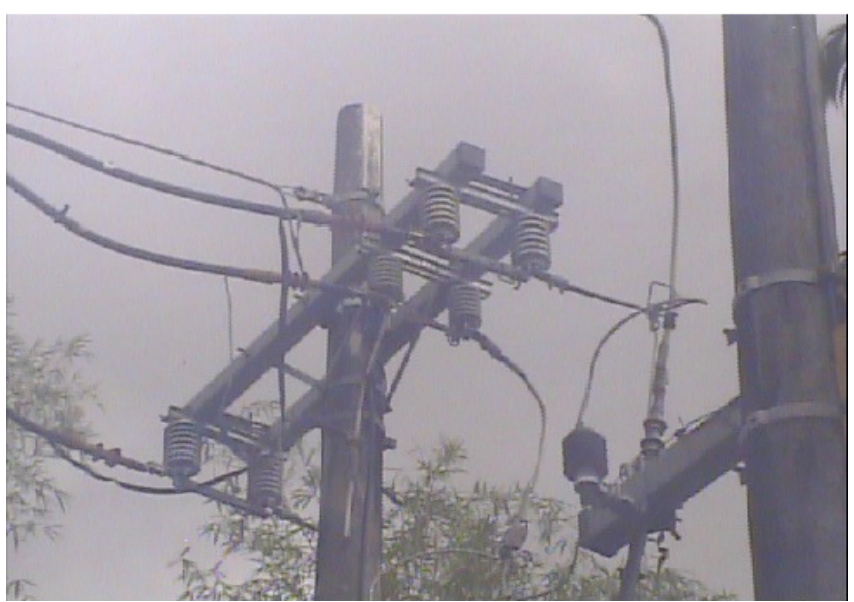

Figura 9. Chave seccionadora de uma rede de $13,8 \mathrm{kV}$.

Fonte: Autor, 2019.

em risco e a segurança da equipe de manutenção em rede aérea energizada (Linha Viva).

Plano de ações/medidas que podem ser tomadas:

- Recomenda-se a desenergização da rede conforme a Nr-10;

- Realizar manobras nos alimentadores
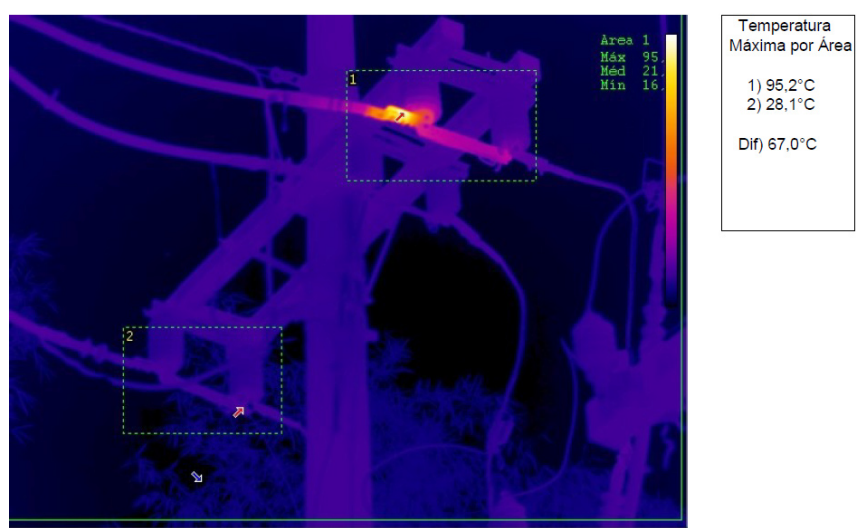

Figura 10. Termograma de uma imagem térmica na chave seccionadora de uma rede de $13,8 \mathrm{kV}$. 
paralelos dando recurso, fazendo assim a diminuição do carregamento do circuito e a redução do valor da temperatura;

- Realizar manobras para deixar essa chave seccionadora em paralelo.

Caso 3: Análise de uma Chave seccionadora de uma rede de $13,8 \mathrm{kV}$, conforme a Figura 11, registrada durante o período diurno.

Conforme a Figura 11 foi detectada a imagem térmica, sendo a temperatura mostrada na Figura $12 \mathrm{em}$ uma chave seccionadora ao qual a fase da rua (de fora) (A) apresenta $150,0^{\circ} \mathrm{C}$, colocando os materiais isolantes

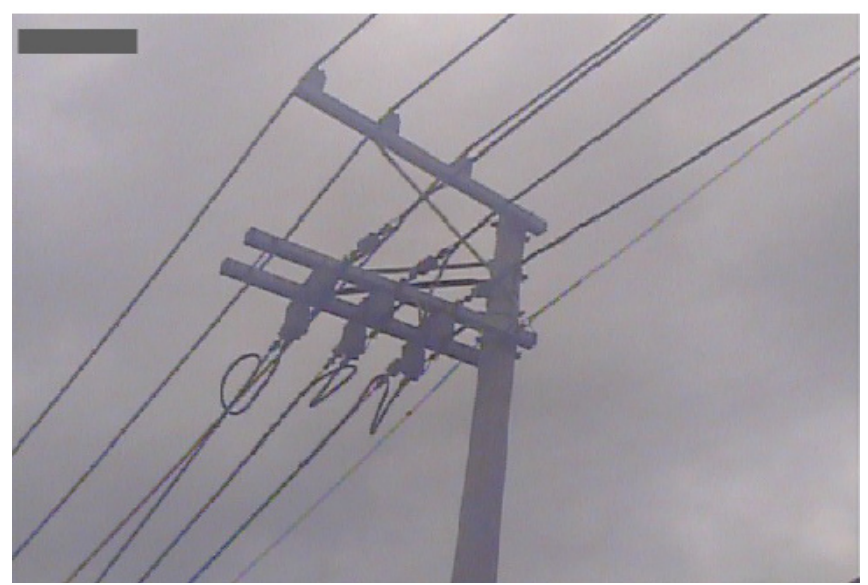

Figura 11. Chave seccionadora de uma rede de $13,8 \mathrm{kV}$. Fonte: Do Autor, 2019.

em risco e a segurança da equipe de manutenção em rede aérea energizada.

Plano de ações/medidas que podem ser tomadas:

- Recomenda-se a desenergização da rede conforme a Nr-10;

- Realizar manobras nos alimentadores
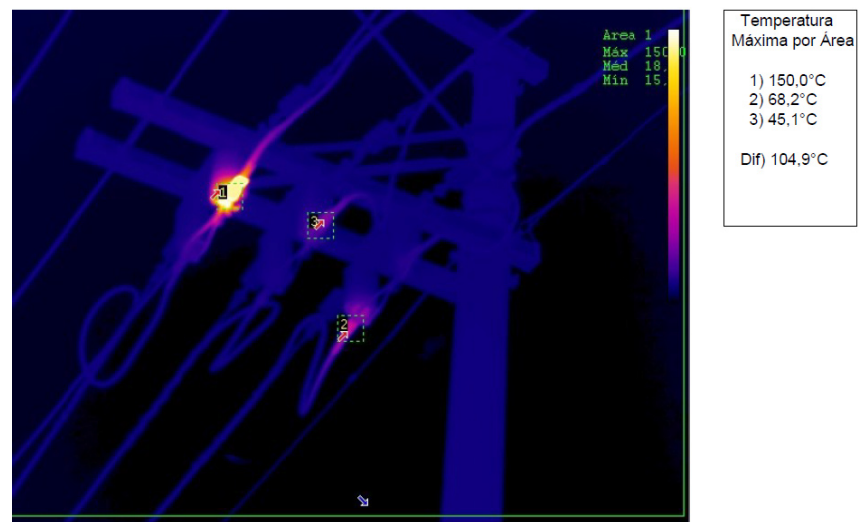

Figura 12. Termograma de uma imagem térmica na chave seccionadora de uma rede de $13,8 \mathrm{kV}$

Fonte: Do Autor, 2019 paralelos dando recurso, fazendo assim a diminuição do carregamento do circuito e a redução do valor da temperatura;

- Realizar manobras para deixar essa chave seccionadora em paralelo.

Caso 4: Análise de uma Chave seccionadora de uma rede de 13,8 kV, conforme a Figura 13, registrada durante o período diurno.

Conforme a Figura 13 foi detectada a imagem térmica, sendo a temperatura mostrada na Figura 14 em uma chave seccionadora ao qual a fase do meio (B) apresenta $104,1{ }^{\circ} \mathrm{C}$, colocando os materiais isolantes em

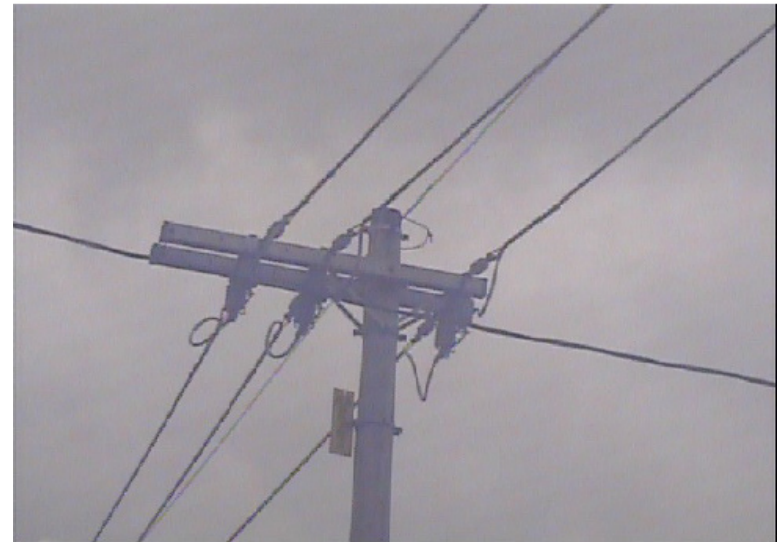

Figura 13. Chave seccionadora de uma rede de $13,8 \mathrm{kV}$. Fonte: Do Autor, 2019

risco e a segurança da equipe de manutenção em rede aérea energizada (Linha Viva).

- Plano de ações/medidas que podem ser tomadas:

- Recomenda-se a desenergização da rede conforme a Nr-10;

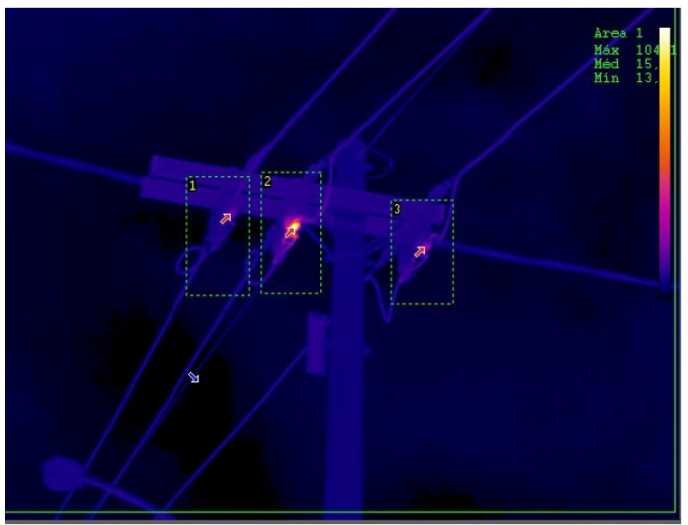

Temperatura Màxima por Área 1) $30,4^{\circ} \mathrm{C}$ 3) $39,0^{\circ} \mathrm{C}$ Dif) $73.7^{\circ} \mathrm{C}$

Figura 14. Termograma de uma imagem térmica no terminal de uma chave seccionadora de $13,8 \mathrm{kV}$

Fonte: Autor, 2019 
- Realizar manobras nos alimentadores paralelos dando recurso, fazendo assim a diminuição do carregamento do circuito e a redução do valor da temperatura;

- Realizar manobras para deixar essa chave seccionadora em paralelo.

Caso 5: Análise de uma chave seccionadora de uma rede de $13,8 \mathrm{kV}$, conforme a Figura 15 , registrada durante o período diurno

Conforme a Figura 15 foi detectada a imagem térmica, sendo a temperatura mostrada na Figura $16 \mathrm{em}$ uma chave seccionadora ao qual a fase de dentro (C)

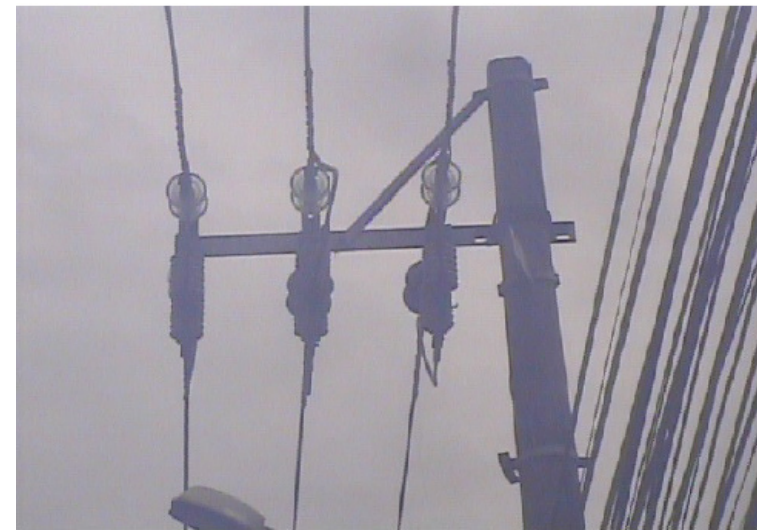

Figura 15. Chave seccionadora de uma rede de $13,8 \mathrm{kV}$. Fonte: Do Autor, 2019

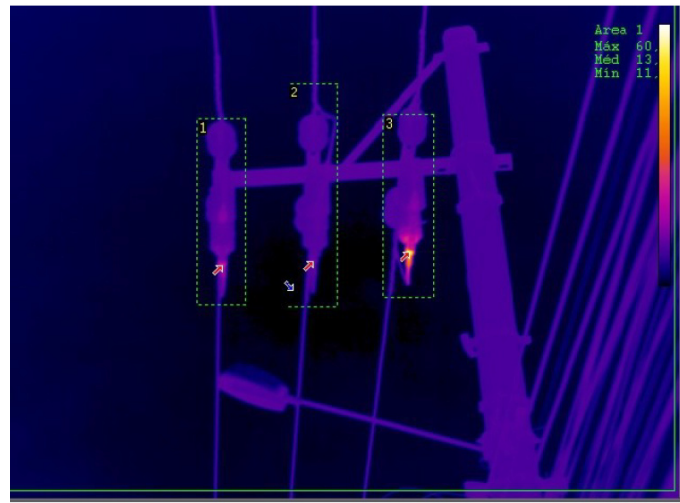

Temperatura Maxima por Area 1) $31,2^{\circ} \mathrm{C}$ 3) $60,5^{\circ} \mathrm{C}$ Dif) $39,7^{\circ} \mathrm{C}$

Figura 16. Termograma de uma imagem térmica na chave seccionadora de uma rede de $13,8 \mathrm{kV}$

Fonte: Autor, 2019

apresenta $60,5^{\circ} \mathrm{C}$, não expondo os materiais isolantes em risco e a segurança da equipe de manutenção em rede aérea energizada (Linha Viva).

Plano de ações/medidas que podem ser tomadas:

Recomenda-se a instalação do jumper isolado (by-pass) a distância antes da isolação da rede elétrica no ponto que será conectado antes e depois no jumper da chave, fazendo a corrente ser dividida pela lei de Kirchhoff consequentemente o valor da temperatura irá diminuir.

\section{Considerações finais e conclusões}

O presente trabalho explica a importância da medição da temperatura para substituição ou reparo de conexão por equipe de manutenção em rede aérea energizada (Linha Viva) com o foco na segurançados eletricistas e o circuito elétrico apontando anomalias térmicas que permitem a identificação de plano mais adequado para execução da atividade, isto podendo contribuir para a diminuição considerável dos acidentes que possam acontecer e as interrupções não programadas por falhas causadas por um aumento da temperatura nos terminais de chaves seccionadoras, fusíveis e jumper com conexão.

O trabalho, em suma, contribui para mostrar que a termografia é uma ferramenta na prevenção de acidentes e falhas do sistema elétrico de potência.

Com a tecnologia tendo grande avanço ao longo dos anos, o equipamento termovisor mostrou atender com grande importância os problemas de manutenções das empresas.

A iniciativa para conscientizar sobre os problemas da falta de inspeção termográfica nas instalações elétricas em prol da segurança dos eletricistas e o sistema elétrico pode ser apresentada em palestras primeiramente dentro da universidade como uma divulgação para obtenção de melhorias a serem seguidas.

$\mathrm{O}$ artigo se conclui em uma proposta de implementação de medidas e ações que venham trazer benefícios para a equipe de manutenção em rede aérea energizada em relação a atingir uma melhoria na segurança dos eletricistas, confiabilidade no sistema elétrico, e a segurança das instalações elétricas em média tensão.

\section{Referências bibliográficas}

Alves, I. C. (2017). Estudo para aplicação de termografia em perdas não técnicas. Vassouras, Rio de Janeiro, Brasil: Universidade Severino Sombra.

Associação Brasileira de Norma técnicas. ABNT NBR 10623. (1991). Mangas isolantes de borracha. ABNT, Rio de Janeiro.

Coutinho B. M.F, Mello L.I, Santa Maria C.L. (2003). Polietileno: principais tipos, propriedades e aplicações. Ciência e Tecnologia,13, 1-13

Hernaski, G R. (2010). Estudo para avaliação de propriedades elétricas e mecânicas de materiais empregados na confecção de ferramentas para "Linha Viva".Curitiba, Paraná, Brasil: Universidade Federal do Paraná.

(2013). Estudo de viabilidade técnica para trabalhos noturnos com redes energizadas.Curitiba, Paraná, Brasil: Universidade Federal do Paraná.

Ministério Do Trabalho - MT. NR-10 - Segurança em Instalações e Serviços em Eletricidade. Aprovada pela portaria n ${ }^{\circ} 598$, de 07 de dezembro de 2004 , publicada no D.O.U. em 8 de dezembro de 2004.

Orion S.A. (2018). Isolantes de Borracha. Recuperado em 02 de maio de 2019, de: https://orionsa.com.br/wp-content/uploads/2018/10/ 


\section{CAT\%C3\%81LOGOS-ISOLANTES-2018.pdf.}

Pinto, M. T. (2013). Termografia em proveito da avaliação de perdas térmicas em equipamentos de subestação de distribuição: Proposição de ações/diretrizes dentro de estratégia de manutenção preditiva. Vassouras: Universidade Severino Sombra.

TEREX RITZ (2018). Cobertura Isolante. Recuperado em 02 de maio de

2019, de: <https://www.terexritz.com.br/produtos/ferramentas-manutencaosistemas-eletricos/coberturas-protetoras-e-lencois/1-aplicacao-manuseio-econservacao/>. 